\title{
Correction to: The effect of intrinsic image memorability on recollection and familiarity
}

\author{
N. Broers ${ }^{1,2} \cdot$ N. A. Busch ${ }^{1,2}$ \\ Published online: 25 May 2021 \\ (C) The Psychonomic Society, Inc. 2021
}

\section{Correction to: Mem Cogn https://doi.org/10.3758/s13421-020-01105-6}

The following affiliation for the two authors of this article was missing in the article as originally published:

University of Muenster, Münster, Germany.

Also, in the original article, the following links to these subchapters: Abstract, Experiment 1, Experiment 2, Results experiment 2, General discussion. This should be: Abstract, Experiment 1, Experiment 2, General Discussion. In addition: for Experiment 1, the subheaders (e.g., Participants, Procedure) have a different size/level compared to subheaders in Experiment 2. They should have the same header level. The design of the headers in Experiment 2 should be the same as in Experiment 1.

The original article has been corrected.

Publisher's note Springer Nature remains neutral with regard to jurisdictional claims in published maps and institutional affiliations.

The online version of the original article can be found at https://doi.org/ 10.3758/s13421-020-01105-6

\footnotetext{
N. Broers

n.broers@wwu.de

Institute of Psychology, University of Münster, Münster, Germany

2 Otto Creutzfeld Center for Cognitive and Behavioral Neuroscience, University of Münster, Münster, Germany
} 